\title{
Combined therapy in the treatment of mixed etiology leg ulcer - case report
}

This article was published in the following Dove Press journal:

Therapeutics and Clinical Risk Management

Jarosław Pasek'

Grzegorz Cieślar²

Aleksander Sieroń ${ }^{2}$

'Institute of Physical Education

Tourism and Physiotherapy, University

of Jan Długosz in Częstochowa,

Częstochowa, Poland; ${ }^{2}$ Department of Internal Medicine, Angiology and

Physical Medicine, School of Medicine with the Division of Dentistry in

Zabrze, Medical University of Silesia

in Katowice, Bytom, Poland
Correspondence: Jarosław Pasek Department of Internal Medicine, Angiology and Physical Medicine, Stefana Batorego St. I5, 4I-902 Bytom, Poland $\mathrm{Tel} / \mathrm{fax}+48327861630$

Email jarus_tomus@tlen.pl

\begin{abstract}
The most frequent causes of leg ulcers are chronic venous disease (CVD) related mainly to venous hypertension and peripheral arterial disease (PAD) related to disseminated atheromatous lesions in lower limb arteries. In $15 \%-21 \%$ of patients, ulcers of mixed venousarterial etiology occur, which are usually more resistant for conservative therapy (compression therapy, pharmacotherapy, wearing elastic stockings, leg elevation and massage, change of lifestyle, and regular physical exercises). The contemporary model of complex therapy of leg ulcers in the course of chronic venous and arterial insufficiency more often also comprises numerous physical therapy procedures as associated therapy. This paper presents beneficial results of treatment applied to a 58-year-old patient with 1-month lasting painful chronic ulcers of both shins of mixed venous-arterial etiology, resistant to conservative therapy, which was performed by using the device Laserobaria-S for local combined physical therapy including simultaneous action of hyperbaric oxygen, extremely low-frequency (ELF) variable magnetic field, and low-energy light radiation. As a result of a 9-week therapeutic cycle consisting of 30 daily procedures, a complete healing of ulcers in both shins with accompanying subsidence of pain and substantial reduction in the intensity of local inflammation around the ulcer was obtained. The patient reported no side effects, and no complications were observed during the therapy.

Keywords: mixed etiology leg ulcer, chronic venous-arterial insufficiency, treatment, combine physical therapy, supplementary therapy, local hyperbaric oxygen therapy, low-energy light therapy, magnetotherapy, Laserobaria-S
\end{abstract}

\section{Introduction}

The most frequent causes of formation of leg ulcers are chronic venous disease (CVD) and more rarely peripheral arterial disease (PAD).

CVD is among the most frequently occurring problems encountered in health care systems in both developed and developing countries. For example, in the United States, more than 30 million people have some form of CVD. ${ }^{1}$ It should be emphasized that prevalence of CVD is 10 times higher than that of PAD. CVD is a major source of morbidity with an incidence of 92 cases per 100,000 hospital admissions annually. Most of the admissions are related to venous leg ulcers, the most advanced clinical manifestation of the disease, occurring in $\sim 0.1 \%-0.3 \%$ of the western population each year, and it increases with age, affecting up to $2 \%$ of the population aged $>80$ years. $^{2-4}$ The annual direct cost of treating CVD in the United States is $\sim 3$ billion dollars, and in Germany, the annual average cost of illness for a patient with a leg ulcer has been estimated at 9,060 euros., , $^{2,5}$

Chronic venous insufficiency (CVI) is a condition resulting from the hemostasis in veins. The main cause of CVI is the injury of the veins transporting blood from lower extremities to the heart. Venous valves have to function efficiently for the blood to 
be able to cope with gravity without problems. Disturbances make a part of the blood return (the so-called venous reflux), and thus remain in the veins, extend them, and hamper their proper functioning. This may lead to the formation of lasting swelling of lower limbs, which in turn may result in chronic trophic lesions or varicose ulcers in the shin. ${ }^{6}$ Actually venous hypertension is considered as primary cause of symptoms of CVI, among them skin lesions resulting in the formation of venous leg ulcers. ${ }^{7}$ Venous hypertension is thought to cause CVI by the following sequence of events: increased venous pressure transcends the venules to the capillaries, impeding flow, low-flow states within the capillaries cause leukocyte trapping, trapped leukocytes release proteolytic enzymes and oxygen-free radicals, which damage capillary basement membranes, then plasma proteins, such as fibrinogen, leak into the surrounding tissues, forming a fibrin cuff, next interstitial fibrin and resultant edema decrease oxygen delivery to the tissues, resulting in local hypoxia which results in the formation of inflammation and tissue loss.

CVI in the area of lower extremity is less frequently caused by narrowing of vascular lumen, loss of patency of the blood vessel, or sub-patency condition, caused by thrombosis or secondary lesions in the course of postphlebitis syndrome. ${ }^{8,9}$ Other risk factors for CVD include older age, family history, female sex, pregnancy, obesity, occupations performed while standing, high-impact physical activity, habits of tobacco smoking and excessive alcohol consumption, and also comorbid conditions such as deep vein thrombosis, superficial thrombophlebitis, and obstructive sleep apnea..$^{3,10,11}$

PAD is caused by disseminated atheromatous lesions in arteries, which lead to constriction or even complete occlusion of blood vessels, with subsequent limitation of blood supply in lower limbs. Due to strong compensatory efficiency of human organism the symptoms of PAD appear relatively late, when the disease is in advanced stage. The incidence of PAD increases with age. Other risk factors for this disease are type 2 diabetes, arterial hypertension, hypercholesterolemia, male sex, and tobacco smoking. ${ }^{12,13}$ The most common symptom of PAD is pain in calf muscles with increasing intensity while walking and subsiding at rest (so-called intermittent claudication) and difficulties in limb motion. Additionally, patients suffer from coldness of the limbs, muscle numbness and spasms, and also muscle hardening after physical activity. In advanced stage of PAD, often a critical lower limb ischemia appears with accompanying strong pain and formation of chronic wounds (ulcers), which are usually very painful, with subsequent necrosis of tissues. Frequently, secondary bacterial infections occur within the area affected by the wound, which become bright red and have inflamed margins. ${ }^{12,13}$ Non-treated ulcers could finally lead to limb amputations which in case of arterial insufficiency are significantly more frequent than those in patients with CVI (1.2\%). ${ }^{14}$

A remarkably high proportion of all leg ulcers are caused by CVD, but in $15 \%-21 \%$ of patients, a mixed venous-arterial etiology of ulcers occur, with coexisting arterial insufficiency during the course of chronic ischemia of limbs. ${ }^{15-17}$ Such ulcers are more resistant for standard therapy, as average time to complete healing for venous ulcers is 5.9 months, while for mixed etiology ulcers, 7.4 months. ${ }^{18}$ Lack of diagnosis of arterial ischemic component of leg ulcer results in inefficacious therapy lasting for many months or even years and sometimes in significant worsening of local status, especially in case of advanced limb ischemia. In order to avoid such problems, it is necessary to pay more attention to the estimation of efficiency of arterial system in patients with leg ulcers, especially before the beginning of high pressure compression therapy. ${ }^{16,19,20}$

Nowadays, the results of treatment of leg ulcers still remain unsatisfactory, despite the contemporary diagnostic and treatment opportunities. Moreover, numerous diseases of veins and arteries, if not treated effectively or not treated at all, may lead to life-threatening consequences, including various systemic manifestations that endanger the health and life of patients or serious complications regarding extremities. $3,13,14,16$

In patients with leg ulcers of various etiology, a complex rehabilitation procedure is required to enable patients to remain self-dependent and move around without aid. ${ }^{21,22}$

The treatment of CVI should be a multi-stage process, in which two main directions of patient management may be distinguished: conservative treatment, and surgical treatment and increased tissue oxygenation. ${ }^{23}$ The aim of the conservative treatment is to reduce the intensity of manifestations already present and to slow down the further progression of the disease. Among the methods of conservative treatment, it is of great importance to have proper and long-lasting application of compression therapy that enables both healing of ulcer and prevention of its recurrence. For venous ulcers, high compression pressures of at least $40 \mathrm{mmHg}$ at the ankle level should be used, and for mixed etiology ulcers, lower pressures are recommended. The conservative therapy also includes pharmacological treatment (pentoxifylline, sulodexide, micronized purified flavonoid fraction (MPFF), and local antiseptic drugs or sometimes systemic antibiotics and for 
mixed etiology ulcers additionally acetylsalicylic acid, anticoagulant drugs, and statins), wearing elastic stockings, leg elevation and leg massages, change of lifestyle - abstaining from condiments (eg, tobacco smoking, alcohol consumption), as well as regular physical exercises (eg, marching, walks, swimming, and cycling). ${ }^{15,24,25}$

The eligibility for surgical treatment is based upon the location of the stenosis/stenoses in blood vessels, the assessment of stenosis degree, and the intensity of complaints; it also takes into account the lack of effects of conservative treatment. ${ }^{24}$

The contemporary management model of complex therapy of leg ulcers in the course of chronic venous and arterial insufficiency more often also comprises the physical therapy procedures as associated therapy. ${ }^{26,27}$ Hyperbaric oxygen therapy (HBOT) or combined therapy procedures, consisting of joint application of HBOT and at least two other physical factors as extremely low-frequency (ELF) variable magnetic field and low-energy light radiation are the modern solution applied. Hyperbaric oxygen affects the human body by eliciting systemic changes related to the functioning of the respiratory and circulatory systems, as well as topical/ local action related to intensification of healing of chronic wounds. Increased oxygenation of tissues results, among others, in acceleration of fibroblast proliferation, faster regeneration of ischemic parts of skin, speeding up the process of granulation tissue growth and epidermization of wounds, intensification of angiogenesis process, as well as improved supply and draining of tissues with and of blood. ${ }^{28}$ ELF variable magnetic field causes improvement of tissue microcirculation, stimulation of angiogenesis and vasodilatation, as well as stimulation of fibroblasts resulting in increased synthesis of collagen, as well as strong analgesic effect related to local inhibition of inflammation nearby ulceration and stimulation of activity of endogenous opioid system. ${ }^{29}$ In turn low-energy light radiation causes among others stimulation of collagen synthesis by activated fibroblasts, improvement of blood supply in tissues nearby ulceration due to vasodilatation effect, and stimulation of lymphatic drainage, as well as strong anti-inflammatory and analgesic effects. ${ }^{30}$

Taking into account that mechanisms of therapeutic action of the above-mentioned physical factors are complementary to one another, in the group of patients with chronic leg ulcerations of various origin, one can expect beneficial effect of simultaneous action of those physical factors on the course of the process of wound healing, which could have an additive or synergistic character.

\section{Case presentation}

A written informed consent has been provided by the patient to have the case details and any accompanying images published.

A 58-year-old patient diagnosed previously with CVD in stage C6EnAsPo of the CEAP classification was admitted to Department of Internal Medicine, Angiology and Physical Medicine of Medical University of Silesia in Katowice due to ulcers of both shins, caused by chronic mixed venous-arterial insufficiency and accompanied by acute pain, which appeared for the first time in his life and lasted for 11 months in spite of the treatment. The medical documentation revealed that the patient had been previously hospitalized a few times during those hospitalizations and in ambulatory treatment, various forms of standard pharmacotherapy were used (pentoxifylline, sulodexide, and local antiseptic therapy), as well as daily local wound management and compression therapy by using stretching stockings were applied, due to above diagnosis, yet with no significant improvement. So far in the patient's treatment, no methods of physical therapy were applied. Additionally, the patient was efficiently treated for arterial hypertension and hypercholesterolemia. He did not suffer from any other comorbid diseases that affect the healing of type 2 diabetes.

The patient was moderately overweight with the body mass index (BMI) value of $27.5 \mathrm{~kg} / \mathrm{m}^{2}$. He did not smoke tobacco, and he used to drink alcohol only occasionally.

The physical examination at admission performed according to Romanelli et $\mathrm{al}^{31}$ revealed extensive trophic lesions in both shins with accompanying numerous shallow ulcers of variable size with maximal surface of a single ulcer $\sim 30 \mathrm{~cm}^{2}$ located around the shin in connection with each other, thus encircling the shin and covering in total of about $25 \%-50 \%$ of its surface. All ulcers had irregular sloping edges, bottom with fibrinous, granulating base, and low exudate levels. Nearby ulcers of persistent inflammatory lesions of the skin of dermatitis type, dark brown in color with accompanying atrophic changes of the hypodermis, were observed. The shins were stretched and very painful, with the presence of slight edema and purulent coating before debridement. Also, a fibrous ring was noted above the ankles, constricting the entire shin circumference (the extremity looked like a champagne bottle standing upside down). Tremulous pulse in lower limb arteries, particularly in the area of dorsal arteries in both feet, posterior tibial arteries, and popliteal arteries, was detected. In Figure 1, the local status before the beginning of therapeutic cycle is presented only for right shin, as it was practically equal as in other one. 


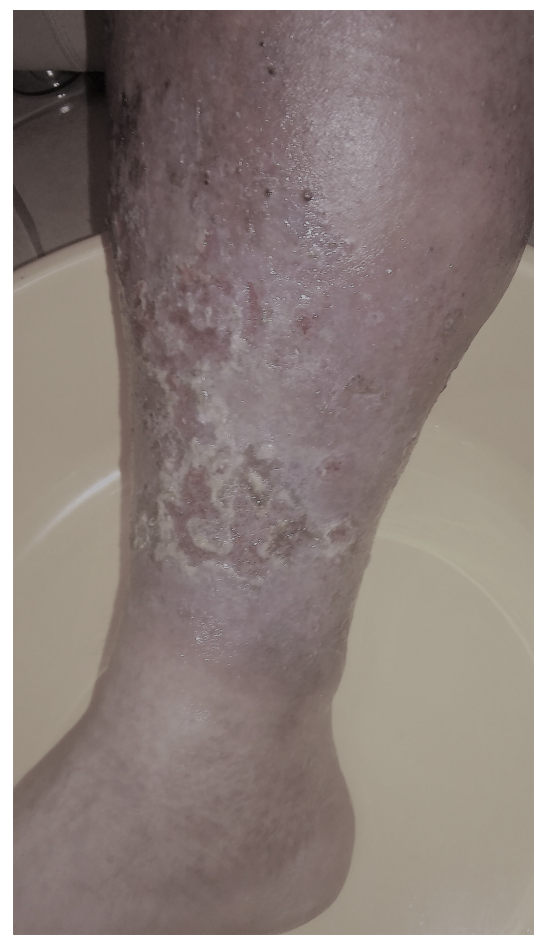

Figure I Local status of patient's shin before the beginning of physical treatment.

In the Doppler ultrasound imaging, numerous sites of stenosis in small saphenous and popliteal veins in both the lower extremities without significant signs of venous reflux, as well as many calcifications in vessel wall, typical for profound atherosclerotic lesions and significant stenosis sites in arteries at various levels, especially in popliteal, radial, posterior tibial, and dorsalis pedis arteries with substantial hemodynamically significant stenosis in most of them, were found.

The value of ankle-brachial index (ABI) for right leg was 0.8 and for left leg was 0.7 , which are indicative of moderate ischemia of both legs in the course of PAD and accepted as end point for high compression therapy.

Based on the results of physical examination, measurement of ABI index, as well as the Doppler ultrasound imaging findings, the shin ulcers were finally diagnosed as mixed venous-arterial ones..$^{20}$

Before and after the end of the treatment, the subjective assessment of accompanying pain intensity was also performed by the patient, with the use of visual analog scale (VAS; 0 points - no pain experienced, 10 points - maximum intensity of pain). Before the beginning of the therapeutic cycle, the score was 8 .

After the consultations (angiologist, vascular surgeon), the patient was found to be eligible for physical treatment by using the device Laserobaria-S (Inventmed Sp. z.o.o., Świętochłowice, Poland), for local combined physical therapy procedures. ${ }^{32}$ This method of treatment of chronic non-healing leg ulcers was approved. During the procedures, the lower extremities placed in the therapeutic chamber were simultaneously exposed to the following physical agents:

1. oxygen, having the pressure of $1-1.5 \mathrm{mBar}$ and flow of about $5 \mathrm{~L} / \mathrm{min}$,

2. ELF variable magnetic field with sinusoidal course of impulse, frequency of $40 \mathrm{~Hz}$, and magnetic field induction of $15 \mathrm{mT}$,

3. low-energy red light with the wavelength of $650 \mathrm{~nm}$ and ultraviolet radiation with the wavelength of $410 \mathrm{~nm}$.

The therapeutic cycle comprised a total of 30 daily procedures, performed once a day for 5 weekdays and interrupted for Saturday and Sunday. The cycle was divided into two series of 15 procedures, with a break of 3 weeks between them. During the procedure, which lasted for 30 minutes each time, the patient was sitting, while both his legs, one by one (the left leg followed by the right one), were placed inside the therapeutic chamber, which was closed by means of a sealing sleeve (Figure 2). After each procedure, in order to provide antisepsis and mechanical protection, the wound was provided with antiseptic dressing, and compression therapy with Coban bandage for 7 hours daily on both the legs was applied. The chamber was disinfected after each procedure. During the therapeutic cycle of Laserobaria-S procedures, a standard pharmacotherapy (pentoxifylline, sulodexide, MPPP-micronized purified flavonoid fraction and acetylsalicylic acid) was also applied.

Throughout the therapeutic cycle, dynamic healing of wounds has been observed, along with gradual generation of new granulation tissue and progressing epidermization process. Ultimately, as a result of therapeutic cycle ( 9 weeks in total), the ulcers healed completely at the same time in both the legs, and moreover, the pain subsided altogether (subjective pain intensity in the VAS score was estimated by the patient as 0 points). Also, a substantial reduction in the intensity of local inflammation around the ulcer was observed. The patient reported no side effects, and no complications were observed during the therapy.

The local status of both the legs after completion of the therapeutic cycle with the use of Laserobaria-S device (a total of 30 procedures) is presented in Figure 3.

The positive result of treatment allowed the patient to return to fully independent life and to come back to his activities of daily living.

After the end of hospitalization, according to actual guidelines, ${ }^{15,25}$ the continuation of modified compression therapy (pressure below $40 \mathrm{mmHg}$ at the ankle level due to 


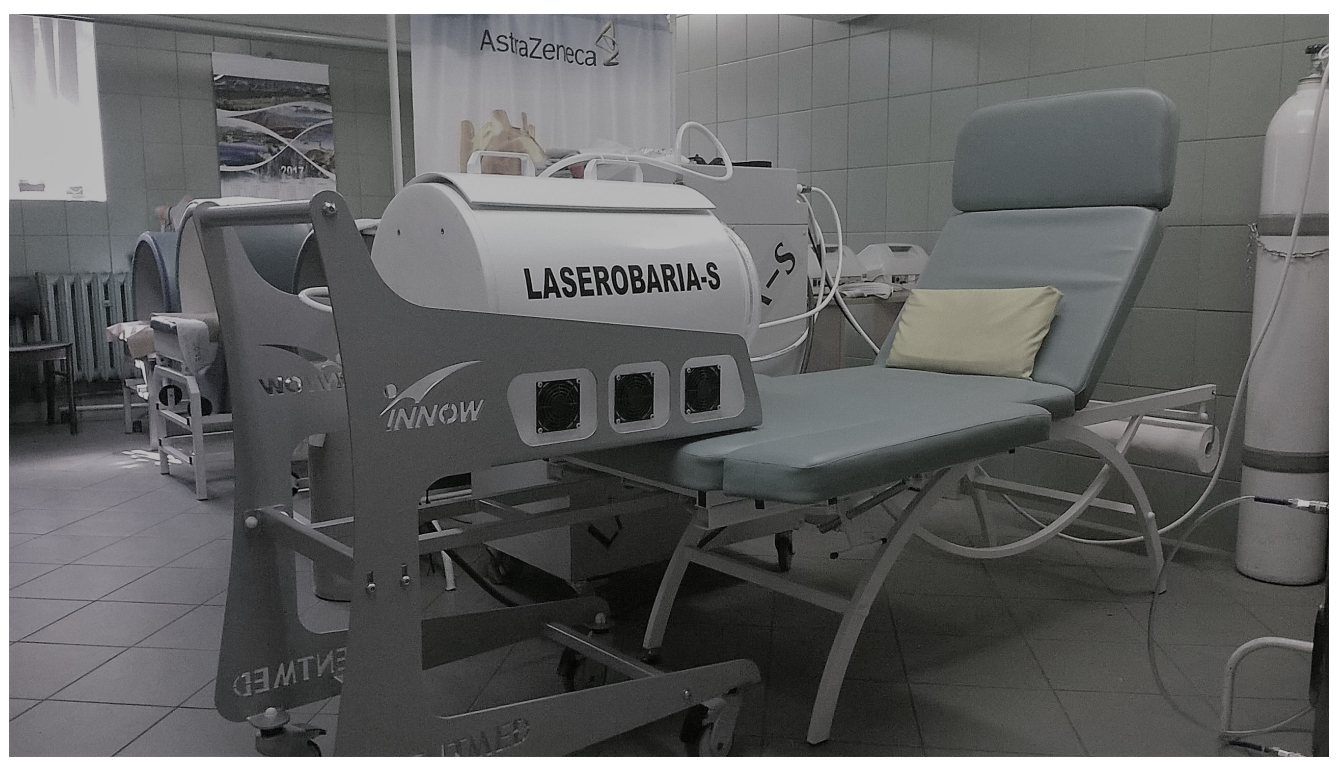

Figure 2 The device Laserobaria-S for local combined physical therapy procedures.

arterial insufficiency) using a stiff system with frequent reassessment and monitoring for ischemia and pressure damage, wearing of elastic stockings, pharmacotherapy (pentoxifylline, sulodexide, MPPP-micronized purified flavonoid fraction, and acetylsalicylic acid), as well as reduction of body mass to the value of BMI $<25 \mathrm{~kg} / \mathrm{m}^{2}$, total avoidance of condiments, and increase of the intensity of physical activity (walking exercises) were recommended.

\section{Discussion}

The search for various solutions that may enhance the efficacy of treatment of chronic wounds still remains a substantial clinical challenge and requires extensive knowledge as well as abilities in treatment planning. In the medical practice so far, this knowledge has often not been complete or limited due to high costs of suitable equipment, thus the application of routine therapeutic procedures prevailed.

In recent years, significant progress has been observed resulting from studying the processes involved in healing of chronic wounds. ${ }^{26,27}$ This is the basis for the introduction of complex therapy with the use of not only one but also numerous innovative therapeutic methods, which is much more efficient affecting both shortening of healing time and improved quality of esthetic results concerning the skin lesions treated. At present, the traditional methods of standard wound care, consisting merely of wound debridement,

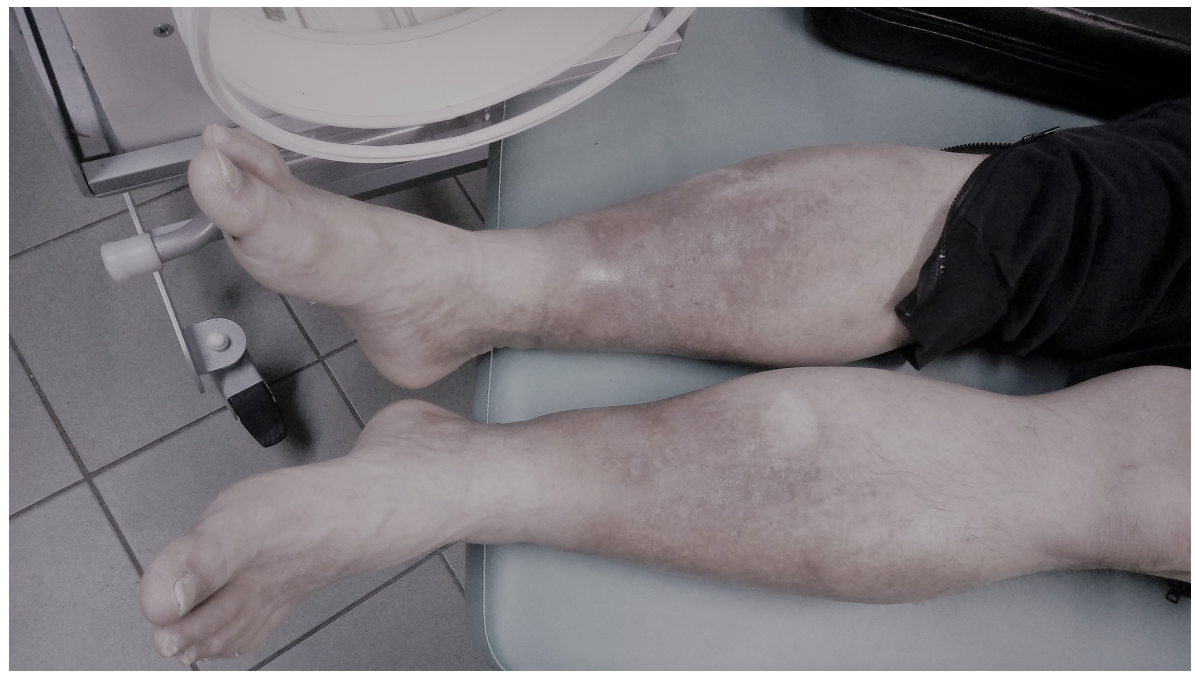

Figure 3 Local status of both the legs after the end of therapeutic cycle with the use of the device Laserobaria-S. 
daily dressing change, application of topical pharmacological substances, and compression therapy, are not sufficient. Physical procedures with suitable configuration of physical parameters prove to have synergies related to intensified epithelization, improved blood supply, nourishment, and oxygenation of tissues, which promote substantially quicker and more effective wound healing. In many cases, physical procedures may be applied as the only efficient method of treatment. ${ }^{26,27}$ Inclusion in the program of complex therapy physical medicine procedures such as local HBOT, magnetotherapy with the use of ELF variable magnetic fields, as well as phototherapy procedures, the mechanisms of which comprise improvement of tissue blood supply and partial oxygen pressure in tissues, thus enhancing regeneration processes and intensifying epidermization processes, hereby reduces the wound healing time and beneficially decreases pain ailments of patients undergoing treatment. ${ }^{26,27,32}$

The results of treatment achieved in the patient described above indicate that the application of physical procedures in the form of combined physical therapy applied by using one device constitutes an efficient method supporting classical wound treatment. The device applied in this method is relatively cheap and easy to operate, and the costs of the treatment including mainly the purchase of hyperbaric oxygen and materials for disinfection, as well as depreciation of the device, are lower as compared to routine treatment (longer time of hospitalization, consumption of more time of nurses and doctors, expensive antibiotics, and wound dressings). ${ }^{33,34}$ Moreover, the method itself is well tolerated by patients and does not cause negative side effects. However, some negative sides of this form of therapy should be mentioned; as for the safety reasons regarding the use of hyperbaric oxygen, there is a need of daily treatment in medical institution with the exclusion of the ambulatory treatment at patient's home and the potential possibility of infection despite disinfection measures after each procedure could not be excluded.

\section{Conclusion}

The application of physical procedures in the form of complex therapy with the use of Laserobaria-S device is potentially effective in patients with chronic mixed venousarterial etiology leg ulcers, as it enables to achieve a complete healing of ulcer and subsidence of pain in relatively short time, without any complications or side effects. In future, after carrying out randomized clinical trials regarding the therapeutic efficacy and safety of this method, it could be an advantageous supplement to the standard methods of treatment of mixed venous-arterial etiology leg ulcers.

\section{Disclosure}

The authors report no conflicts of interest in this work.

\section{References}

1. Gloviczki P, Comerota AJ, Dalsing MC, et al; Society for Vascular Surgery; American Venous Forum. The care of patients with varicose veins and associated chronic venous diseases: clinical practice guidelines of the Society for Vascular Surgery and the American Venous Forum. J Vasc Surg. 2011;53(5 Suppl):2S-48S

2. Mallick R, Raju A, Campbell C, et al. Treatment patterns and outcomes in patients with varicose veins. Am Health Drug Benefits. 2016; 9(8):455-465.

3. Mcardle M, Hernandez-Vila EA. Management of chronic venous disease. Tex Heart Inst J. 2017;44(5):347-349.

4. Petherick ES, Cullum NA, Pickett KE. Investigation of the effect of deprivation on the burden and management of venous leg ulcers: a cohort study using the THIN database. PLoS One. 2013;8(3):e58948.

5. Augustin M, Brocatti LK, Rustenbach SJ, Schäfer I, Herberger K. Cost-of-illness of leg ulcers in the community. Int Wound J. 2014;11(3): 283-292.

6. Barańska-Rybak W, Komorowska O. Skin lesions in venous disorders. Forum Medycyny Rodzinnej. 2012;6(1):35-42.

7. Lee BB, Nicolaides AN, Myers K, et al. Venous hemodynamic changes in lower limb venous disease: the UIP consensus document. Int Angiol. 2016;35(3):236-352.

8. Jawien A, Grzela T. Epidemiology of chronic venous insufficiency. Przegl Lek. 2004;8:30-34.

9. Bergan J. Molecular mechanisms in chronic venous insufficiency. J Dtsch Dermatol Ges. 2006;4:627-628.

10. Rabe E. Study B vein. Phlebology. 2006;59:179-186.

11. Padberg F Jr, Cerveira JJ, Lal BK, Pappas PJ, Varma S, Hobson RW. Does severe venous insufficiency have a different etiology in the morbidly obese? Is it venous? J Vasc Surg. 2003;37(1):79-85.

12. Au TB, Golledge J, Walker PJ, Haigh K, Nelson M. Peripheral arterial disease - diagnosis and management in general practice. Aust Fam Physician. 2013;42(6):397-400.

13. Gogalniceanu P, Lancaster RT, Patel VI. Clinical assessment of peripheral arterial disease of the lower limbs. $N$ Engl J Med. 2018;378(18):e24.

14. Tsai S, Dubovoy A, Wainess R, Upchurch GR Jr, Wakefield TW, Henke PK. Severe chronic venous insufficiency: magnitude of the problem and consequences. Ann Vasc Surg. 2005;19(5):705-711.

15. Harding K, Dowsett C, Fias L, et al. Simplifying Venous Leg Ulcer Management. Recommendations from an Expert Working Group. London: Wounds International Enterprise House; 2015:1-25.

16. Callam MJ, Harper DR, Dale JJ, Ruckley CV. Arterial disease in chronic leg ulceration: an underestimated hazard? Lothian and Forth Valley leg ulcer study. Br Med J (Clin Res Ed). 1987;294(6577):929-931.

17. Moffatt CJ, Franks PJ, Doherty DC, Martin R, Blewett R, Ross F. Prevalence of leg ulceration in a London population. QJM. 2004;97(7): 431-437.

18. Sauer K, Rothgang H, Glaeske G. BARMER GEK Heil- und Hilfsmittelreport 2014. Siegburg: Asgard Verlagsservice GmbH; 2014. Available from: http://www.zes.uni-bremen.de/uploads/News/2014/140916_ Heil_Hilf_Report_2014.pdf. Accessed August 13, 2018.

19. Słowiński P, Krosny T, Raciborski W, Staszkiewicz W. The current views on the formation and treatment of venous leg ulcers. Prog Med. 2012;3:27-34.

20. Mcdermott MM, Criqui MH. Ankle-Brachial Index Screening and Improving Peripheral Artery Disease Detection and Outcomes. JAMA. 2018;320(2):143-145.

21. Caggiati A, Rosi C, Franceschini M, Innocenzi D. The nature of skin pigmentations in chronic venous insufficiency: a preliminary report. Eur J Vasc Endovasc Surg. 2008;35(1):111-118.

22. Szewczyk MT, Jawień A, Cwajda J. Integral disturbances of skin in chronic venous insufficiency and crural ulceration. Post Derm Alergol. 2005;3:145-149. 
23. Partsch H. Varicose veins and chronic venous insufficiency. Vasa. 2009; 38(4):293-301.

24. Geryk J, Bieniaszewski L. Chronic venous insufficiency-patophysiology, clinical picture and treatment. Choroby Serca i Naczyń. 2009;6: $138-143$

25. Wittens C, Davies AH, Bækgaard N, et al. Editor's Choice-Management of Chronic Venous Disease: Clinical Practice Guidelines of the European Society for Vascular Surgery (ESVS). Eur J Vasc Endovasc Surg. 2015;49(6):678-737.

26. Pasek J, Stanek A, Pasek T, Sieroń A. Physical medicine as an opportunity for improving the health state of patients with vascular diseases. Acta Angiol. 2012;18(3):93-98.

27. Pasek J, Cieślar G, Sieroń A. Selected procedures of combined therapy. Rehabil w Prakt. 2017;5:17-24.

28. Bhutani S, Vishwanath G. Hyperbaric oxygen and wound healing. Indian J Plast Surg. 2012;45(2):316-324.
29. Pasek J, Pasek T, Sieron A. Magnetostimulation in the treatment of crural vein ulceration. Int Wound J. 2012;9(5):566-569.

30. Landau Z. Topical hyperbaric oxygen and low energy laser for the treatment of diabetic foot ulcers. Arch Orthop Trauma Surg. 1998;117(3): $156-158$.

31. Romanelli M, Dowsett C, Doughty D, et al. World Union of Wound Healing Societies (WUWHS) Position Document. Advances in wound care. The Triangle of Wound Assessment. London: Wounds International; 2016:1-30.

32. Sieroń A, Pasek J. Laserobaria-S new apparatus in physical medicine to the treatment of chronic wounds. Rehabil w Prakt. 2016;4:68.

33. Probst S, Seppänen S, Gethin G, et al. EWMA Document: Home Care Wound Care. J Wound Care. 2014;23(5 Suppl):S1-S44.

34. Hampton S, Lindsay E. Empowering patients to take control of leg ulcer treatment through individualised management. J Wound Care. 2005; 14(5):238-240.

\section{Publish your work in this journal}

Therapeutics and Clinical Risk Management is an international, peerreviewed journal of clinical therapeutics and risk management, focusing on concise rapid reporting of clinical studies in all therapeutic areas, outcomes, safety, and programs for the effective, safe, and sustained use of medicines. This journal is indexed on PubMed Central, CAS,

\section{Dovepress}

EMBase, Scopus and the Elsevier Bibliographic databases. The manuscript management system is completely online and includes a very quick and fair peer-review system, which is all easy to use. Visit http://www.dovepress.com/testimonials.php to read real quotes from published authors.

Submit your manuscript here: http://www.dovepress.com/therapeutics-and-clinical-risk-management-journal 